\title{
Yfançonas, burguesas e rústicas: algumas reflexões sobre viuvidade e herança no texto normativo Vidal Mayor de Vidal de Canellas (séc. XIII)
}

Yfançonas, burguesas and rústicas: some reflections on widowhood and inheritance in the normative text Vidal Mayor of Vidal de Canellas (13th century)

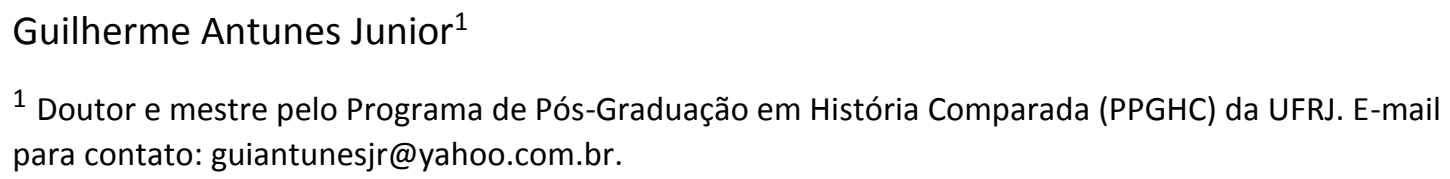

\section{Resumo}

O Vidal Mayor é compilação de leis atribuída ao bispo de Huesca, Vidal de Canellas, a pedido de Jaime I de Aragão, em 1247. Em minha análise, destaco ao Liber Sextus, capítulo foral cujo tema central é o instituto jurídico chamado de arras. Chamo atenção para a viuvidade, isto é, uma condição ambígua que expressa as diferenças existentes entre homens e mulheres quanto ao direito à herança e o usufruto dos bens.

Palavras-chave: viuvidade; Reino de Aragão; história do direito.

\begin{abstract}
The Vidal Mayor is a compilation of laws attributed to the Bishop of Huesca, Vidal de Canellas, at the request of James I of Aragon, in 1247. In my analysis, I highlight the Liber Sextus, the main theme of which is the legal institute called Arras. I draw attention to widowhood, that is, an ambiguous condition that expresses the differences between men and women in the right to inheritance and the enjoyment of property.
\end{abstract}

Keywords: widowhood; Kingdom of Aragon; history of law.

\section{Introdução}

A trajetória do manuscrito Vidal Mayor (ms. Ludwig XIV, 6) por si mesma já é uma aventura da história, dados os incidentes que envolvem a redescoberta do documento. Para resumir o intento, sabemos que o proprietário que o adquiriu foi Luis Franco y 
López, advogado e prefeito em Zaragoza, no século XIX. Em 1906, o manuscrito saiu da Espanha e foi para coleção particular de Charles William Dyson Perrins, em Malvern, na Inglaterra, comprado das mãos de uma terceira pessoa, Charles Fairfax Murray. O Vidal Mayor tinha sido vendido a Murray pelo filho de Franco y López. A catalogação foi feita em 1920 por George Warner, mas a primeira análise da obra só foi realizada em 1949 pelo medievalista inglês Joan Evans (LACARRA DUCAY, 2012, p. 10). Somente em 1956, o hispanista sueco Gunnar Tilander transcreveu o códice aragonês por completo em uma versão crítica, além de reproduzir as 156 miniaturas - ainda que em tamanho reduzido e em branco e preto. Sabe-se que, em 1958, o Vidal Mayor, junto com outros manuscritos, foi para os Estados Unidos, e retornou à Europa para um casal de colecionadores de arte: o Instituto Peter e Irene Ludwig, em Aachen, Alemanha. Finalmente, um novo traslado levou o códice para os Estados Unidos mais uma vez. A Fundação J. Paul Getty, em Santa Monica, Califórnia, adquiriu o Vidal Mayor em 1983 e continua sendo sua fiel depositária até hoje, apesar das reivindicações espanholas para repatriação do patrimônio.

A maior parte da existência do manuscrito foi nas mãos de particulares, o que explica sua pouca difusão e interesse nos meios acadêmicos ainda hoje, se comparado com outros códices como, por exemplo, as Cantigas de Santa Maria, de Alfonso X. Com a política de disponibilizar as imagens do Vidal Mayor coloridas, e em alta resolução, ${ }^{192}$ além de programas educativos voltados para história da arte, cresce também o volume de pesquisas, principalmente entre o público especializado fora da Europa e dos Estados Unidos. Assim, cheguei até a ele depois de ler citações de outros autores. Trata-se de um texto único, sem cópias conhecidas e de origem ainda em discussão.

Jaime I de Aragão, durante as cortes de Huesca em 1247, ordenou que fossem compilados os textos de caráter foral pertencentes à tradição aragonesa. Essa tarefa foi confiada ao bispo de Huesca, Vidal de Canellas, o qual elaborou dois manuscritos: Liber in Excelsis ou Compilatio Maior, obra em latim que tinha como referência normativa o

\footnotetext{
192 O J. Paul Getty Museum disponibiliza, além das iconografias em alta resolução, bibliografia atualizada sobre a obra. Ver: https://www.getty.edu/art/collection/objects/1431/unknown-vidal-de-canellas-andprobably-michael-lupi-de-candiu-et-al-vidal-mayor-spanish-about-1290-1310/. Acesso em 06-jun-2020.
} 
direito romano. Infelizmente, não se conservou o texto latino, a não ser três páginas, sendo o prólogo e algumas citações, hoje depositado na Biblioteca Nacional de Espanha (ms. 7391). O mesmo Vidal de Canellas também ficou responsável pela redação de outro texto, o chamado Compilatio Minor ${ }^{193}$, uma sistematização reduzida, com estrutura próxima da Compilatio Maior, mas não se trata de uma derivação, isto é, uma não serviu como fonte da outra. Em suma, como observa Delgado Echeverría, o Compilatio Minor não é um resumo ou uma readaptação, mas uma produção que ocorreu paralelamente (1989, p.76), sendo que sua principal fonte é o direito aragonês, e não o romano. Não há nenhum manuscrito sobrevivente do ano em que se celebraram as Cortes de Huesca, em 1247, mas cópias posteriores, sendo as mais antigas do início século XIV, tanto em romance como em latim. Entretanto, a data de produção do Vidal Mayor continua incerta, possivelmente depois de 1952 (LACARRA DUCAY, 2002, p. 7), não obstante os especialistas do J. Paul Getty Museum apontam os anos de 1290 e 1310 como o período de elaboração do manuscrito.

Pois bem, o Compilatio Maior, em sua versão em língua romance, será conhecido como Vidal Mayor, ${ }^{194}$ isto é, o Compilatio se manteve no território da coroa de Aragão, sendo utilizado para consulta jurídica, porém, sem aplicação estrita de suas leis. O Vidal Mayor é um documento da metade do século XIII, cópia do "original" latino feita sob supervisão, redação e distribuição em nove códices, que ficou a cargo do bispo de Huesca Vidal de Canellas, sendo, finalmente, aprovado pelas cortes de Huesca. Posteriormente, mas com data incerta, o notário navarro Miguel López de Çandiu traduziu o códice para o vernáculo (DELGADO ECHEVERRÍA, 1989, p. 53). O idioma do Vidal Mayor é formado por variantes entre o navarro e o aragonês, com interpolações latinizantes ${ }^{195}$.

\footnotetext{
193 Este manuscrito recebe outras denominações: Fori Novi; Fueros de Aragón; Compilação de Huesca ou Código de Huesca. Ver: PÉREZ MARTIN, 1989-1990, p. 18.

${ }^{194}$ Se trata de “... un tercer manuscrito realizado con posterioridad a 1252, posiblemente en Pamplona, lo que elimina la teoría de que la difusión de la compilación de Vidal de Canellas no fue tan amplia como era de esperar" LACARRA DUCAY, 2002, p. 7).

195 Há várias discussões acerca da precisão do idioma vernacular. Trata-se de uma seara que não pretendo discutir aqui por fugir do objeto que abordo. Há autores que afirmam se tratar da língua romance em navarro (GRANERO FERNÁNDEZ, 1980); em aragonês com interpolações em latim (DELGADO ECHEVERRÍA, 1989); e em navarro-aragonês (LACARRA DUCAY, 2012).
} 
Em relação à estrutura documental, o Vidal Mayor está dividido em nove códices, com 277 fólios e 156 miniaturas de diferentes tamanhos. O primeiro fólio do livro I contém um prólogo em que o autor confere a Jayme I o Conquistador o atributo de ordenar a produção do fuero. ${ }^{196} \mathrm{Em}$ seguida, há uma ordenação dos conteúdos, como um índice, apresentando os temas que abordam cada um dos nove livros. A cada item, há uma inscrição em latim com tradução para o romance. ${ }^{197}$ Cada um dos capítulos está subdividido em parágrafos, segundo a edição de Gunnar Tilander, correspondente a um tema.

Neste espaço, analiso os papéis referentes às relações de gênero no Liber Sextus, del Dreito de las Arras, do Vidal Mayor, capítulo que trata de 21 temas, grosso modo, referentes aos contratos matrimoniais entre as famílias dos pretendentes, além de outros acordos entre marido e esposa e as responsabilidades com os filhos. Faço um recorte analítico comparando três grupos que são mencionados em diferentes parágrafos: Yfançonas, burguesas e rústicas. Essas três categorias são diferentes segundo os critérios identitários de Vidal de Canellas. Para tanto, utilizo como fontes textual as edições de Gunnar Tilander, publicada pelo Instituto Editorial Reus, em 1957; e cotejo com a edição da Diputación Provincial de Huesca com o Instituto de Estudios Altoaragoneses, de 1989. Por fim, foi fundamental o glossário navarro-aragonês publicado em 1956 por Gunnar Tilander e reeditado em 2019 com textos introdutórios de José Ignacio López Susín y Francho Nagore Laín.

\section{Liber Sextus, o direito às arras e o matrimônio}

O contexto da convocação das cortes de Huesca, e a consequente elaboração da legislação aragonesa de 1247, foi o fim das campanhas militares valencianas contra os

\footnotetext{
196 “Nos don Jaymes, por la gracia de Díus, rey d’Aragón et de Maillorgas et de Ualentia, conte de Barçalona et de Urgel et seynnor de Montpesler" (CANELLAS, 1997, p. 7).

${ }^{197}$ Assim, o primeiro livro trata: I. De las santas iglesias sagradas e de los ministros d'eillas; II. De los iuditios e d'aqueillas cosas que deuen ser feitas en iuditio; III. De las prescriptiones que quieren dizir de los tempos que faze omne, teniendo el heredamiento em possessión, assí como es aynno et día o encara XXXI aynno e I día, segunt que es la conditión de la cosa que tiene possessión; IV. De la pena que deuen auer aqueillos que nesciamente pleiteyan; V. De las cosas emprestadas; VI. Del dreito de las arras; VII. De la conitión de la ynfançonia; VIII. De la tregoa et de la patz; IX. De los acusadores (CANELLAS, 1997, p. 2056).
} 
muçulmanos com a tomada do castelo de Biar, em Alicante, no ano de 1245 , marcando a conquista do reino de Valencia (GARCÍA EDO, 2018, p. 103). Há que se destacar que ainda havia uma dispersão legislativa no reino de Aragão, assim como em toda Península Ibérica, cuja apreensão do direito dependia de cada municipalidade. Assim, a Europa ainda estava longe de construir uma unidade normativa generalizada, algo que só veio a se consumar com a formação das nações após o século XV. No reino de Valência, por exemplo, após a conquista de Jaime I em 1239, houve a confecção do Costum, uma lei municipal primária outorgada pelo monarca, sendo a Curia ou Cort o órgão diretivo e administrativo da municipalidade. Mais tarde, no ano de 1245, com a emergência de um poder mais autônomo, quatro Jurats eram escolhidos por ricos homens da cidade através de um privilégio real: "Cuatro prohombres electos en Jurats admnistrarán, governará y regirán el núcleo urbano y su término en nombre del monarca, a quien deberán brindar de fidelidade y homenaje com anterioridade a la toma de posesión del cargo" (NARBONA VIZCAÍNO, 1995, p. 27). Esse privilégio sofreu modificações a partir de 1278 , o que afetou a instância do poder cidadão e municipal. O exemplo indica que o poder de caráter foral era complexo e dependia de acordos com diferentes grupos políticos, não por acaso, o Compilatio Maior foi desaprovado em função de uma legislação mais enxuta, relacionada com as características aragonesas e maior rejeição a preceitos do direito romano.

A respeito especificamente da fonte histórica, é preciso destacar algumas características. O primeiro tema do Liber Sextus aborda os contratos conjugais, em especial as arras, De ontratibus coniugum, es a saber: de los contractos que fazen marido et muiller. As arras têm origem tanto no direito romano, conhecida por Donatio propter nuptias, quanto no germânico, chamado morgengabe - "doação da manhã" (FERNÁNDEZ-SANCHO, 2006, p. 83). As arras são a doação que o marido dá à mulher no âmbito dos acordos referentes à união e, é claro, são variáveis segundo o texto foral e o contexto histórico. As discussões acerca desse instituto se dão também por se tratar de heranças que seguem com a esposa ou se estendem aos filhos. A arra é um conceito histórico-jurídico amplo, por isso elas vêm acompanhadas de parágrafos que debatem a viuvez, a parentela, as condições dos herdeiros, a posição social da família, os laços de 
consanguinidade, etc. Ao mesmo tempo, as arras aparecem em fontes normativas medievais como parte dos contratos de compra e venda de bens móveis e imóveis, e não apenas como referência a pactos matrimoniais. No Vidal Mayor, esse instituto ganha importância normativa devido ao vínculo da mulher ao bem móvel ou imóvel, pois a esposa não poderia renunciar suas arras, nem parte delas, sem o consentimento do seu pai, caso estivesse vivo, ou de um parente próximo. ${ }^{198}$ No direito castelhano medieval, ${ }^{199}$ especialmente entre os séculos XI ao XIII, os diferentes textos jurídicos também apontam para um tipo de doação feita à esposa, antes ou depois do casamento, podendo ser usufruído pelo pai ou parentes da noiva, ou como uma garantia caso ela se tornasse viúva.

$\mathrm{Na}$ economia do casamento, os bens que podem entrar em disputa para usufruto da família foram matéria de preocupação de diferentes textos jurídicos medievais. No Vidal Mayor, as discussões sobre a capacidade de dividir bens e direitos, assim como temas como a virgindade, a viuvidade, a resolução de disputas, as heranças, a orfandade, etc. são juízos abordados na normativa aragonês em forma de tópicos que, muitas vezes, em um texto confuso, busca tratar de maneira abrangente cada um dos pontos. De qualquer forma, ainda sobre o direito às arras, o Vidal Mayor dispensa atenções à mulher que herdará bens de seu marido em caso de viuvez, o que aponta para um sistema de proteção das camadas nobiliárias quanto à transmissão de propriedades fundiárias e outros objetos de valor.

A viuvidade é particularmente abordada como uma condição em que há necessidade de salvaguardar tanto as carências materiais (menester) da esposa quanto as responsabilidades da herança que deve ser garantida aos filhos. Há precaução para que não se empenhem os bens materiais caso a mulher tenha filhos. Essa condição explicita as diferenças e contradições nas relações de gênero, cujo núcleo das disputas é desigual e os discursos normativos sobrepõem os homens - maridos, pais e filhos - às

\footnotetext{
198 "Ninguna muiller non puede renunciar a sus arras en todo o em partida nin puede dar a su marido nin puede camiar con instrumento o sin instrumento, si por ventura esto non fiziere por consentimento de su padre..." (CANELLAS, 1997, p. 208).

${ }^{199}$ Gámez Montalvo recorre as Siete Partidas, ao Fuero Viejo de Castilla, ao Fuero Juzgo e ao Fuero Real para abordar as arras como doação do marido à esposa, sinalizando as diferenças segundo as normativas e as tradições jurídicas germânicas e romanas (1998, p. 136-146).
} 
mulheres em estado de viuvidade. Assim, a mulher não poderá arrendar ou alienar suas arras, salve se por imprescindibilidade causada por pobreza. ${ }^{200}$

No início do título Do dreito de las arras, Vidal de Canellas pondera que o direito a bens depende de regras nos mecanismos sociais de transmissão de heranças, visto que destina aos yfançones, "La muiller que se casa con yfançon, quoantas queire eredades et quoalossequeire possessiones aja al marido, tres daqueillas possessiones ho heredades, non de las millores nin las piores mas de las comunales, li deve ser assignadas em arras..." (CANELLAS, 1997, p. 209). Essa preocupação quanto às obrigações da herança deve-se à manutenção dos bens em torno da família. Mas esse parágrafo é destinado a uma categoria muito específica da baixa nobreza do reino de Aragão, os ifanzones - ou yfançones e fijos dalgo. Trata-se de um grupo urbano, economicamente muito variado, que poderia ocupar cargos reais, ou mesmo atuar como profissionais liberais ou de cunho jurídico (FALCÓN PÉREZ, 2008, on line). Portanto, "La muiller que se casa con yfançon" tem sua herança mais detalhada e é maior o número de parágrafos correspondentes às arras no Vidal Mayor.

Há no texto foral sutilezas quanto às condições para o recebimento de heranças em caso de viuvidade (viduage), sendo a maior parte delas considerações relacionadas à quantidade de imóveis que o marido possuía antes e depois do casamento. Para que a mulher receba os bens, eles devem estar garantidos em forma de arras, portanto, dependerá de acordo prévio. Para se evitar conflitos, o Vidal Mayor estabelece que se o marido possuir mais de três propriedades, pelo menos três delas devem ser garantidas como herança (heredades), e assim regressivamente: “... et si el varón ha tant solament dos heredades, aqueillas dos li deven assignar [dadas] a su muiller por arras; el si tant solament ha I possessión, aqueilla li deve assignar por arras a su muiller" (CANELLAS, 1997, p. 209). Essas condições criteriosas para recebimento das propriedades fazem parte da elaboração de discursos sobre a manutenção dos vínculos familiares para a

\footnotetext{
${ }^{200}$ Empero, si mester [necessidade] ovier e fuere mingoada [diminuídas], puede a 1ạ possessión daqueillas arras empeynnar o las dos o todas, si tant grant menester há, empero, si ha fillo o fila que deva heredar em aqueillas arras [et] li quiere proveer a eilla de las cosas que há menester, la madre non podrá empeynar ninguma cosa daqueillas heredades o de las arras por razón que está em su viudage (CANELLAS, 1997, p. 210).
} 
administração da circulação de bens. Tanto que a mulher não poderia utilizar as arras como penhor, nem mesmo como garantia de algum empréstimo, salvo se chegar a uma situação de penúria (fuere mingoada), "Empero, si mester oviere et fuere mingoada, puede I possessión daqueillas arras empeynnar o las dos o todas, si tant grant menester há..." (CANELLAS, 1997, p. 209). Não há instrução parecida para homens caso sejam eles os viúvos. Mas essa regra possui uma observação caso haja filhos que possam herdar as propriedades "... si ha fillo o filla que deva heredar en aqueillas arras [et] li quiere proveer a eilla de las cosas que ha menester, la madre non podra empeyn[a|r ninguna cosa daqueillas heredades o de las arras por razón que está en su viduage" (CANELLAS, 1997, p. 209). Aliás, a observância quantos a existência de herdeiro é uma particularidade do Vidal Mayor na normatização dos aspectos relativos aos contratos de casamento.

As dívidas contraídas antes ou depois do matrimônio representam preocupação particular no foral de Aragão. Há expressamente a obrigação de pagamento das dívidas pelos herdeiros, mas dentro de regras que respeitem o patrimônio e a condição de viuvidade. Em relação às despesas mortuárias, “... deve ser catado [observado] que aqueilla part daqueillas espensas [despesas] que propriament en aqueilla mortailla [funeral] son feitas" (CANELLAS, 1997, p. 211), verificam-se se os bens deixados são suficientes para o pagamento do dispêndio com os rituais funerários, como velas, armaduras, enxoval e oferendas: “... candelas, en la pórpora, en los paynnos que son necessarios a la sepultura, en las oblaciones et las cosas semeillables a éstas..." (CANELLAS, 1997, p. 211). Essa proposição sobre o pagamento das dívidas com o sepultamento ocorre porque as despesas funerárias poderiam entrar no testamento do falecido (destin, ordenamiento), daí as especificações quanto às obrigações em se pagar esses débitos.

Como se trata de um grupo muito variado social e economicamente, os yfançones estavam sujeitos a uma administração territorial que fosse capaz, ao menos em tese, de responder a sucessivas contrações de empréstimos e dar conta de litígios recorrentes em função das dívidas que permaneciam junto com a viuvidade. Dessa forma, o texto normativo deixa explícito que, ao menos, a mulher poderia ficar com a 
metade, "Si varón et aqueillas deudas son feitas ante el matrimonio, aqueillas deudas deven ser pagadas de los bienes movibles, sacando primerament a mittad de la muiller et sacadas aqueillas cosas que la muiller deve tomar ante de la partilla [divisão]" (CANELLAS, 1997, p. 211). Retiradas a fração da mulher, cuja proporção é quase sempre a metade, contabiliza-se os bens móveis e imóveis até que se chegue ao valor devido. $E$, caso ainda não fosse suficiente, a mulher deveria arcar com parte de suas arras "... et encara, si todas estas cosas no abastan, las arras son obligadas ad aqueillas deudas, si aqueillas arras non fueron dadas con instrumento público" (CANELLAS, 1997, p. 211). Ou seja, a garantia para que as arras não fossem comprometidas, era a declaração por meio de instrumento público, o que, novamente, dá a dimensão do controle comunitário do direito e da justiça, “... quar [a saber], si con instrumento público, ad aqueillas deudas non son obligadas aqueillas arras" (CANELLAS, 1997, p. 211). O mesmo ocorre com dívidas cujas despesas são comuns entre marido e mulher. Caso não se prove que as dívidas contraídas pelo marido não eram para usufruto de ambos, as arras devem ser usadas para quitação do débito.

Os bens não móveis também poderiam ser usados para garantias de empréstimos, nesse caso, embora não se exponham exemplos, referem-se à produtividade da atividade econômica da qual se dedica o infançón, podendo ser rural ou comercial. Para o pagamento da dívida, é necessário o produto de um ano do rendimento, correndo o risco de se perder a propriedade caso não seja o suficiente para honrar os credores "... et si los fruitos de I aynno non cuemplen [bastam], deven eillos tener aqueillas possessiones ata que del todo sean pagados" (CANELLAS, 1997, p. 212). Outro ponto é que o marido deve pagar as dívidas que a esposa contraiu antes do matrimônio com a metade dos bens herdados por ele. Caso ela contraia a dívida durante o casamento e ela não seja comerciante, "usava manifestament mercandería", ele não tem a obrigação de saldar o débito, possivelmente como uma forma de proteger as propriedades dos homens yfançones, “... empero, si aqueilla muiller no usa tal officio, el marido nunqua pagará aqueilla deuda por eilla durando el matrimonio" (CANELLAS, 1997, p. 212). Mas os filhos devem pagar as dívidas, se são herdeiros, ou abrir mão de suas heranças. Já quando as arras estivessem garantidas em forma de pagamento, o 
Vidal Mayor estabelece que o marido deve prover em moeda, no valor de 500 sueldos, tendo este bens móveis ou imóveis. ${ }^{201}$

A viuvidade era uma condição perpétua para ambos e também uma forma de usufruir dos bens móveis, como propriedades rurais, por exemplo. Mas, para as mulheres, havia possibilidade de perder as arras caso houvesse indícios de traição, como descreve o Livro VI: "Otrosí, si la muiller, el su marido muerto, oviere manifestamente alguno adulterio o que faga fornicio com eilla, luego deve perder los bienas de su viudage" (CANELLAS, 1997, p. 209). O mesmo não ocorre com o homem caso exista adultério. Até mesmo o espólio usual, cotidiano, é objeto de divisão entre os herdeiros do morto, demonstrando as disputas por itens inerentes à sobrevivência material na viuvez. Há atenção para divisão de vestidos, adornos, joias, roupas de cama (paynnos): “... deven ser partidas entre eilla et sus fillos en tal guisa que eilla aya sus vertidos et aqueillos afeitamientos que son ditas yoyas et I leito de los millores paynnos que sea en aqueilla casa (...) et I vaso de plata et captiva" (CANELLAS, 1997, p. 210). Os animais de carga e cavalgadura representam formas de exploração animal para sobrevivência humana, além de garantir a venda ou troca desses valiosos bichos "... et I mula guisada por cavalgar et I azembla [azêmola, mula de carga] et dos bestias d'arar com sus apertos" (CANELLAS, 1997, p. 210). O índice de objetos é extenso, como um inventário, e procura-se abranger roupas pessoais, mobiliário, ferramentas etc.: "Empero todas las cosas entre la madre et los fillos deven ser partidas (...) I las calderas, I de las aixadas..." (CANELLAS, 1997, p. 210). Entende-se que esses itens garantiriam alguma dignidade à viúva e aos filhos, além do amparo quando se entendia que o marido era o provedor da família.

Ainda relação à viuvidade, o Vidal Mayor faz uma distinção entre os yfançones e outros grupos sociais, embora não pareça uma separação rígida, nem mesmo se trata, claro, de uma "divisão de classes", porque o texto busca equiparar com os mesmos

\footnotetext{
${ }^{201}$ La muiller yfançona deve ser dotada en $D$ sueldos quoando el su marido possedeixe los bienes non movibles; los quoales $D$ sueldos li deven ser assignados en aqueillas possessiones que ha o aurá depués, movibles o non movibles, por los quoales $\mathrm{D}$ sueldos, luego que el matrimonio fuere feito, maguer que [mesmo que] mención non sea feita de las arras, todos los bienes del marido, los que ha et deve aver, li son obligados en caillando [de forma tácita, secreta], assí como si expressamente fuessen las arras establidas del comienço (CANELLAS, 1997, p. 212).
} 
direitos e obrigações essas mulheres, as cipdadanas e as infançonas. No título 272, De eodem, em continuidade a questões sobre herança, o texto se dedica a "muiller cipdadana o de burgo" (CANELLAS, 1997, p. 213), cuja preocupação inicial é sobre dívidas que devem ser pagas em caso de falecimento do marido, cuja abordagem sobre os deveres do pagamento dos débitos é próxima ao título anterior a respeito dos infançons. Quanto às arras, a mulher dita citadina ou burguesa, só poderá solicitar esse direito caso exista documento público comprovando-o, "Empero la muiller çipdadana o burgesa no aurá ren de arras ni ninguna cosa por nompne de [conceito de] arras, si expressament no es dotada con instrumento publico" (CANELLAS, 1997, p. 213). Vê-se que tornar sua condição manifesta à luz da comunidade é uma medida de controle das famílias e da circulação dos bens pela esfera pública, embora seja uma noção distante de como a conhecemos hoje, mas no nível de poder comunitário sem as prerrogativas modernas do Estado. No mesmo parágrafo, essa mulher çipdadana ou burgesa pode gozar de suas arras caso não tenha filhos, ou se os filhos morrerem logo após o parto. Mas a condição para que ela tenha acesso ao direito é ela não ter outro marido ou algum amante "... encara que, depués que viudó, se case o non toviere castidat en outra guisa" (CANELLAS, 1997, p. 213).

Outra categoria é mencionada, além das citadinas e da pequena nobreza: tratase da mulher rústica ou vilã, rústica o villana. Mesmo esses grupos precisam ser dotados de algum bem para sua sobrevivência. ${ }^{202}$ Curiosamente, sob o olhar apressado da leitura da fonte, pode-se apontar que se discorre acerca de mulheres ligadas fundamentalmente ao trabalho da terra. Porém, os bens de que deveriam ser dotadas essas viúvas poderiam significar algum tipo de ascensão, ou pelo menos, um estrato social intermediário. Ao listar esses bens, o texto chama atenção para a necessidade de se deixar uma casa de doze vigas, um yugada ${ }^{203}$ de vinha e uma arroba de trigo, e ainda

\footnotetext{
202 Muiller rústica o villana deve ser dotada en sus bodas de [una] casa [de] XII vigas et de I arinçada de vinna et de un campo en el quoal aya sempnadura de I arrovo de trigo, empero, si el marido quisiere, dotar la puede em quoanta se quiere quantidat o en muitas heredades o possessiones, avidas et de las que podrá aver (CANELLAS, 1997, p. 213).

${ }^{203}$ Segundo o Dicionário de Comércio Medieval: "Medida de peso o capacidad y medida de tierra viña, olivar o huerta, que equivale a 400 estadales, derivada de "arienzo" (de plata) y ampliamente
} 
o marido poderia deixar outras posses se quisesse. Entretanto, como nos demais grupos, há muitos códigos - sempre complexos quanto à interpretação - que garantem ou não as arras a mulher. Há, novamente, a publicização da solicitação do direito, mas esse mesmo direito às arras é ameaçado caso não seja feita menção explícita da promessa do marido antes do matrimônio: "Empero, si, ante el matrimonio feito, de las arras non fuere feito mención, eilla non podrá depués demandar arras, ni el marido será tenido de dar li arras, si por aventura non li quisiere dar" (CANELLAS, 1997, p. 215). Trata-se, sim, de proteção dos bens maritais para que a mulher não reivindique nada que não seja por contrato.

Os historiadores nas últimas décadas se intrigaram com as esferas subalternizadas mencionadas nas fontes. Não se furtaram a questionar a dinâmica social de grupos fora das tão bem documentadas, entre elas, a aristocracia, a nobreza e o alto clero, sempre visto de cima. Robert Fossier sublinha que o casamento camponês seguia regras tais quais a de outros grupos sociais e com os cuidados relativos aos bens: “... el matrimonio campesino fue el de los sencillos: una mutua atracción, vigilada, sin duda, por los parientes a fin de evitar cualquier desastre material o moral, una dilectio por tanto y un consentimento (consensus)" (FOSSIER, 1985, p. 25). Mesmo Fossier trabalhando com documentação distinta, alguns pontos podem ser interessantes para pensarmos alguns aspectos do Vidal Mayor, em uma escala, claro, limitada ao devido texto jurídico aragonês. De fato, há uma vigilância quanto ao destino das arras, as quais acabam permanecendo com a viúva, caso ela não tenha filhos, garantindo, pelo menos no campo normativo, a manutenção do direito. ${ }^{204} \mathrm{O}$ ponto que chama atenção na fonte é que, se a mulher perder o filho, portanto, não terá herdeiros, perderá o direito às arras. A conservação dessa prerrogativa ocorre quando há a viuvez, quando a "... muiller

documentada durante toda la Edad Media". Disponível em: https://www.um.es/lexico-comerciomedieval/index.php/v/lexico/20813/aranzada. Acesso em 3-fev-2021.

${ }^{204} \mathrm{Et}$ si arras li fueren assignadas a eilla, si oviere criatura del marido la quoal veniere a luz en este mundo, sol una hora que sea biva, aqueilla muiller et toda su criatura biva et muerta luego pierde las arras, maguer que la criatura, de que nasció por algun tiempo biva, luego morió. Et si muerta nasciere, non nozdrá [prejudicará] a la madre en ren mas que si non fuesse nascida. Otrosí si la muiller sin criaturas venciere al marido de vida, aurá [disporá] las arras que li fueron assignadas porá todas sus voluntades [disporá livremente]; encara [aún, además, todavia] si casare otra velz o muitas o en otra guisa non toviere castidat, non perdrá sus arras en ninguna guisa" (CANELLAS, 1997, p. 214-5). 
sin criaturas venciere al marido de vida", ou seja, o marido morra antes poderá dispor livremente das arras. E ainda, mesmo que ela se case novamente, mais de uma vez, ou ainda tiver amante, "non toviere castidat", não perderá o direito.

O matrimônio poderia ter ido muito além de uma união contratual que previa o dote, os esponsais e as arras, chegando até mesmo a um instituto que previa certa precaução para proteção jurídica durante um possível desamparo na viuvidade, especialmente da esposa. Mesmo nessa categoria, chamada de rústica, faz-se uma espécie de inventário, novamente, destacando o que deveria ser deixado para esposa e, caso ela tivesse filhos, o direito garante a ela a metade dos bens: "La muiller aurá otrosí de las cosas movibles las quoales el marido et la muiller avian mientre bivian et de las ganancias movibles o non movibles que fizieron aurá la meytad" (CANELLAS, 1997, p. 215). Assim, a metade significa "todas las sus vestiduras éntegrament et las yoyas et 1 leito de los millores paynnos [roupa de cama] que son en casa et dos bestias de las millores de casa que sean de arar con sus instrumentos de arar et una hostilla [enxoval] de todas las naturas [espécies] de las hostillas dobladas" (CANELLAS, 1997, p. 215). Mais uma vez, a atenção aos instrumentos de trabalho e aos bens domésticos, como a roupa de cama. Possivelmente, todos esses objetos eram imprescindíveis para a sobrevivência em sociedades pré-industriais, constituindo valorosos recursos.

\section{Conclusão}

Havia uma multiplicidade de fueros particularistas nos diferentes reinos da Península Ibérica no século XIII. Muitos desses textos normativos tinham caráter comercial, como o de Jaca; militar, como o de Zaragoza; ou de conselho, a exemplo dos fueros de Extremadura, Cataluyd, Daroca, Teruel e Albarracín (SARASA, 1995, p. 380). Não obstante, os fueros tinham dificuldades em se impor, sobretudo, porque não estamos falando de sociedades baseadas no estado de direito, em que as normas formam um império jurídico. As demandas locais, os costumes e os conflitos gerados por políticas reais, criaram um caldo fervilhante cujo direito é um fragmento dos complexos discursos em ebulição, ao menos durante todo o século XIII, “... permanece 
em toda parte essa sobreposição e essa convivência, muitas vezes harmonizando-se, muitas vezes integrando-se, por vezes chocando-se, entre direito comum e direitos particulares..." (GROSSI, 2014, p. 273). Por vezes, os fueros se tornam fontes históricas que apresentam em suas entrelinhas essas disputas por direito, poder e representação.

Quando o Vidal Mayor aborda três grupos sociais, aparentemente distintos em si, sublinha que os conflitos existentes na sociedade iam além do acesso às arras e os outros acordos que envolviam o matrimônio. O direito aragonês estava em construção e envolvia debates entre o direito romano e o consuetudinário quando, desde 1247, o direito aragonês "... quedaba unificado y todos los fueros anteriores eran derogados, los "foristas" trataron de resistir y mantener sus viejas recopilaciones, pues deseaban ante todo conservar su independência (CARABIAS ORGAZ, 2013, p. 59). Trata-se de acomodar dialeticamente perspectivas unificadoras de Jaime I e, ao mesmo tempo, preservar direitos já consolidados culturalmente. De fato, a proteção econômica das mulheres viúvas esbarra, contraditoriamente, com os deveres dessas mesmas mulheres em relação aos deveres matrimoniais. Assim, a viuvidade é mais que uma condição de ausência do outro após a morte do cônjuge, senão uma nova circunstância jurídica, cuja dimensão simbólica é ambígua ao tentar garantir alguma dignidade social mas, ao mesmo tempo, vigiar a circulação das riquezas familiares.

No Vidal Mayor, em especial o Libro VI, existem os bens chamados de comuns, ou seja, aqueles que pertencem à propriedade do casal, conseguidos com o casamento, em uma comunidade conjugal. São tanto bens móveis quanto imóveis, além daqueles que se conseguiram por meio de atividades comerciais, provenientes de lucros com os negócios. Também, heranças ou doações, faziam parte do espólio matrimonial. Pois bem, a viuvidade, especialmente da mulher, colocava todos os bens em disputa para que se discutisse a origem e o destino daquilo que se herdava. Os filhos, por exemplo, foram preponderantes para que os testamentos e a continuidade do pertencimento dos bens fossem mantidos com a viúva. Lembrando que aqueles bens eram condicionados às dívidas e aos acordos intrafamiliares anteriores ao matrimônio. Mulheres casadas com yfançones, como vimos, estavam sujeitas a uma legislação mais detalhada e mesmo rigorosa quando se tratava de heranças. Isso porque essas camadas intermediárias da 
nobreza poderiam sofrer maior vigilância comunitária para se evitarem descumprimentos de contratos. Ao mesmo tempo, as arras tinham valor relativo, por escrituração, conservando assim a vigilância da sociedade perante os acordos públicos.

Já os grupos ditos citadinos ou burgueses, o texto de Canellas é mais enxuto, preocupando-se com elementos relativos às dívidas e a manutenção dos bens. Já vimos que a mulher de burgo perderia as arras caso ela tenha filhos, mesmo que a criança viva por pouco tempo "... luego las pierde quoando oviere fillo o filla, la quoal, viva seyendo, veniere a luz en este mundo, et encara que por poco momento biva" (CANELLAS, 1997, p. 213). Mas o direito às arras é relativo, pois depende de haver instrumento público comprobatório, como já mencionei. A proteção aos herdeiros, inclusive, prevê a perda do direito à gestão dos bens da mulher. Neste ponto, o Vidal Mayor é ainda mais explícito quanto à importância do conselho municipal, outorgando aos membros do poder comunitário as decisões sobre a boa administração dos bens móveis que, “...a muiller començare de destruir las arras (...) o de aillenar maliciosament o de apiorar, podrán cobrar aqueillas arras por l'alcalde, governando a eilla en las sus cosas que ha menester" (CANELLAS, 1997, p. 213). Ou seja, se a mulher começar a desperdiçar o dote, aliená-lo maliciosamente ou penhorá-lo, poderão cobrar providências ao alcaide para que ele gerencie esses bens.

Esses aspectos relacionados à viuvidade são variáveis segundo homens e mulheres, provavelmente, pelo entendimento de que a esposa deveria prover com filhos o marido, ou seja, garantir herdeiros à linhagem. Não obstante, elas são mencionadas mais vezes como uma categoria cuja justiça assegura desvantagens jurídicas a elas em contraste com a valorização do marido, da família e da comunidade. Há parágrafos especificamente destinados à viuvidade da mulher, mas ignoram-se as situações em que o homem poderia estar na mesma condição como, por exemplo, a traição conjugal, que prevê uma punição material com a perda das arras, "De quoalsequiere condición que sea la muiller, pierde las arras por siempre si fiziere adulterio viviendo el marido (CANELLAS, 1997, p. 215). Como dito, não há referências à perda de bens do marido caso exista adultério da parte dele, evidenciando que uma mulher viúva estava secundarizada à condição de procriadora e ao reconhecimento 
comunitário desse estado social. Há provisões de seguridade caso a mulher passe por situações de pobreza e abandono, como mencionado, mas essa hipótese é ocasional e significa uma contradição em si quando comparada às demais situações desiguais de gênero no Vidal Mayor.

Antes de estabelecer diferenças de privilégios entre yfançonas, burguesas e rústicas, Vidal De Canellas prioriza o direito dos viúvos e dos filhos, reposicionando as mulheres horizontalmente, para além de distinções sociais ou simbólicas, tornando o gênero o elemento definidor e o limite de ações de cada um. Aqui tomo emprestado uma ideia de Silleras Fernández $(2004$, p. 186) que, embora trabalhando com fontes e períodos diferentes da coroa de Aragão, a viuvidade era uma condição ambígua, pois, as mulheres não desfrutavam a liberdade no luto, mesmo possuindo bens e riquezas, porque os códigos morais, a perda de poder político e as profundas diferenças de privilégios em relação ao viúvo, colocavam-nas nas incertezas de uma não-posição.

\section{Referências Bibliográficas}

\section{Documentação}

CABANES PECOUR, María de los Desamparados et alii (Org). Vidal Mayor de Vidal de Canellas - Edición, introducción y notas al manuscrito. Zaragoza: Libros Certeza, 1997.

TILANDER, Gunnar. Vidal Mayor - Traducción aragonesa de la obra In excelsis Dei Thesauris de Vidal de Canellas - vocabulário. Textos introductorios de José Ignacio López Susín y Francho Nagore Laín. Zaragoza: Prensas de la Universidad de Zaragoza, 2019.

TILANDER, Gunnar. Vidal Mayor - Traducción aragonesa de la obra in excelsis dei thesauris de Vidal de Canellas. 3 vols. Madrid: Instituto Editorial Reus, 1957.

UBIETO ARTETA, A. et alii (Org). Vidal Mayor - edición, introducción y notas al manuscrito. Huesca: Diputación Provincial de Huesca; Instituto de Estudios Altoaragoneses, 1989.

\section{Bibliografia}

CARABIAS ORGAZ, Miguel. Versiones de la Compilatio Minor o Fueros de Aragón - siglos XIII-XV. e-Spania, n.o 32, 2019. Disponível em: http://journals.openedition.org/espania/30234. Acesso em 06-jun-2020. 
Miguel. La compilación de Huesca - apuntes sobre el proceso de redacción. Aragón en la Edad Media, n.ำ24, p. 55-70, 2013.

DELGADO ECHEVERRÍA, Jesús. Vidal Mayor - Un libro de fueros del siglo XIII In: UBIETO ARTETA, Agustín (Org.). Vidal Mayor - Estudios. Huesca: Excelentísima Diputación Provincial-Instituto de Estudios Altoaragoneses, 1989. p. 43-81.

FALCÓN PÉREZ, María Isabel. Los Infanzones de Aragón en la Edad Media. Zaragoza: Institución Fernando el Católico, 2008. Disponível em: http://journals.openedition.org/mcv/3734. Acesso em 22 de mar. de 2021.

FERNÁNDEZ-SANCHO TAHOCES, Ana Suyapa. Las donaciones otorgadas con ocasión del matrimonio de la mujer. Granada: Comares, 2006.

FOSSIER, Robert. Historia del campesinado en Occidente Medieval. Barcelona: Crítica, 1985.

GARCÍA EDO, Vicent. Los orígenes del derecho general aragonês - del fuero de jaca a los fueros de Aragón de 1247. Aragón en la Edad Media, n.ㅇ 29, 2018, p. 91-126.

GARCÍA HERRERO, Maria de Carmen. Del nacer y el vivir - fragmentos para una historia de la vida en la Baja Edad Media. Zaragoza: Institución Fernando el Católico, 2005.

GONZÁLEZ OLLÉ, Fernando. Vidal Mayor, texto idiomáticamente navarro, Revista de Filología Española, no 84, 2004, p. 303-346.

GRANERO FERNÁNDEZ, Juan Garcia. Vidal Mayor - version romanceada navarra de la Maior Compilatio de Vidal de Canellas. Anuario de história del derecho español, no 50, 1980, p. 243-264.

GROSSI, Paolo. A ordem jurídica medieval. São Paulo: Martins Fontes, 2014.

SARASA, Esteban. De la reordenación interior del espacio tradicional de la expansión mediterránea - los nuevos horizontes económicos y la ermergéncia de la sociedad civil (1134-1276) In: IRADIEL, Paulino et alii. Historia Medieval de la España Cristiana. Madri: Cátedra, 1995. p. 307-392.

LACARRA DUCAY, Maria Carmen. El manuscrito del Vidal Mayor - Estudio históricoartístico de sus miniaturas In: LACARRA DUCAY, Maria Carmen (Org.). La miniatura y el grabado de la Baja Edad Media en los archivos españoles. Zaragoza: Institución Fernando el Católico, 2012. p. 7-44.

LUQUIN BERGARECHE, Raquel. La donación propter nuptias en el régimen común y foral - sus retos en el actual contexto social. Revista Jurídica de Navarra, no 50, 2010, p. 59143. 
MONTALVO GÁMEZ, Francisca Maria. Régimen jurídico de la mujer en la familia castellana medieval. Granada: Comares, 1998.

NARBONA VIZCAÍNO, Rafael. Valencia, município medieval - poder político y luchas cidadanias (1239-1418). Valencia: Ajuntament de Valencia, 1995.

OTERO VARELA, Alfonso. Las arras en el derecho espanol medieval. Anuario de historia del derecho español, n.․ 25, 1955, p. 189-210.

PÉREZ MARTIN, Antonio. La primera codificación oficial de los fueros aragoneses - las dos compilaciones de Vidal de Canellas. Glossae - Revista de Historia del Derecho Europeu, no 2, 1989-1990, p. 9-80.

RODRIGO-ESTEVAN, Maria Luz. Representaciones artísticas en torno a la vida una imagen de la sociedad medieval aragonesa In: LACARRA DUCAY, María del Carmen. Arte y vida cotidiana en época medieval. Zaragoza: Institución Fernando el Católico, 2008. p. 267-308.

SILLERAS FERNÁNDEZ, Nuria. Widowhood and Deception - Ambiguities of Queenship in Late Medieval Crown of Aragon. In: CRAID, M. et alii (Orgs). Shell games - scames, frauds and deceits (1300-1650). Toronto: University of Toronto, 2004. p. 185 - 207. 